Boise State University

ScholarWorks

Sociology Faculty Publications and Presentations

Department of Sociology

4-1-2009

\title{
Recidivism Among Child Sexual Abusers: Initial Results of a 13 Year Longitudinal Random Sample
}

Steven Patrick

Boise State University

Robert Marsh

Boise State University 


\title{
Recidivism Among Child Sexual Abusers: Initial Results of a 13 Year Longitudinal Random Sample
}

\author{
Steven Patrick and Robert Marsh \\ Boise State University
}

\begin{abstract}
In the initial analysis of data from a random sample of all those charged with child sexual abuse in Idaho over a 13 year period, only one predictive variable was found that related to recidivism of those convicted. Variables such as ethnicity, relationship, gender and age differences did not show a significant or even large association with recidivism. The only variable that seemed to show both a significant and almost moderate association to recidivism was the Risk Assessment in the Sex Offender Evaluation re-offense. Comparisons were made to prior research as well as a discussion of implications of the sex offender evaluation for the legal process. Finally, a call for the continued need for further research is discussed.
\end{abstract}

\section{Introduction}

Seemingly daily, the media reports another heinous case of child sexual abuse. The more extreme the crime, the more media attention it receives. Even academic research has reported child sexual abuse as a crisis (Anderson, Mangels, \& Landsam, 2004). This has resulted in a flurry of legislation across the country increasing the sentences for child sexual abuse and even legislation to monitor convicted child molesters after they have completed their sentences (Petrunik, 2003). While child sexual abuse is undoubtedly a heinous crime, much of this legislation is based on dubious media reports that exaggerate the problem (Cheit, 2003; Jones, Finkelhor and Kopiec, 2001; Kappler and Potter, 2004). There are even some instances of legislatures trying to create two strike laws for child sexual abusers (Petrunik, 2003). These laws consume massive resources and offer no assurance of reducing the incidence of child sexual abuse. More research is needed on all accepts of child sexual abuse but in some ways most urgently in the area of recidivism for child sexual abuse. And more importantly, politicians need to look at sound research and make policy on empirical evidence rather than media hysteria. This work reports the initial analysis of a 13 year longitudinal random sample of adults convicted of child sexual abuse in the state of Idaho.

\section{Literature Review}

There has been a limited amount of research on recidivism among child sexual abusers. Among the best is a 25 year study conducted in Canada (Langevin, Curnoe, Fedoroff, Bennett, Langevin and Peever, 2004). This article reported that repeat offenders were more likely to be poor and minority members but offered no theoretical explanation. This Canadian longitudinal study showed recidivism rates of child sexual abuses over 25 years. Other longitudinal research has shown great variability in results. Several other empirical reports show that recidivism among sex offenders is generally low (Hagan \& Gust-Brey, 2000; Prentky, Lee, Knight, and Cerce, 1997), but they all point to the problematic measurement of child sexual abuse recidivism. Other researchers report that while child molesters were less likely to recidivate than non-sex offenders, those recidivating were responsible for the majority of sexual abuse recidivism (Hanson, Scott \& Steffy, 1995). They offer recommendations for using past criminal behaviors to predict future criminal behavior of the same type (Hall, 1996). 
Other research reports that demographic and relational variables affect recidivism. Greenberg, Bradford, Firestone, and Curry (2000) showed that child sex offenders with "acquaintance" relationships to the victim were more likely to recidivate that those with "relative" relationships to the victim. Another analysis showed that those males who molest male victims were more likely to recidivate than those males who abuse female children (Freund and Watson, 1992). Some research showed that males who abuse younger victims were more likely to recidivate (Danni and Hampe, 2000). Other research reported that child sex offenders were more likely to be minorities (Langevin, 2004; Tzeng, Robinson and Karlson, 1999). Also, some research has shown that child sex offenders were at long term risk of recidivism meaning that time a risk becomes an important measure (Langevin, etal., 2004; Prentky, Lee, Knight and Cerce, 1997). Finally, while the evaluation of sex offender treatment was limited, some research showed that this treatment can reduce recidivism (Marsh and Walsh, 1995; McAlinden, 2005; Shanahan and Donato, 2001).

A number of researchers have attempted to compare child sex offenders to non-sex offenders showing some similarities and other differences (Gudjonsson and Sigurdsson, 2000). Cullen, Smith, Funk and Haaf (2000) reported that the courts showed no significant differences in their handling of sex and non-sex offenders. Other research showed that more research is needed comparing the costs and benefits of incarceration verses treatment and the treatment of victims (Shanahan \& Donato, 2001). Bickley and Beech (2001) reviewed the literature and found methodological and/or theoretical problems with all the research in this area. In any case, more research is needed and it is hoped that this initial analysis of a longitudinal random sample of convicted child sex offenders will begin to fill in the gaps in the literature and ultimately lead to theory based predictions.

Theories of the etiology of child sexual abuse seem sparse and this work will be no real exception to this trend. If child sexual abuse is a crime, like other crimes, then main stream criminological theories should be applicable. Some main stream theories have been applied, such as social learning theory and social control theory, with limited results (Bickley and Beech, 2001). The majority of theories applied to child sexual abuse have been psychological theories and most of those have been clinical in nature (Sawle and Kear-Colwell, 2001; Bickley and Beech, 2001; Joyce, 1995). It seems obvious that more theory is needed in this area as most empirical work has reported little more than statistical association in their results (again, this work will not greatly challenge this trend).

Methods

In 1991, the authors began their over 15 year collaboration on a state mandated annual census of child sexual abuse cases filed in district courts in Idaho. To collect the annual census data on child sexual abuse, the researchers travel to all 44 counties reporting offenses and examine the district court files. Once collected, data from the court documents are entered into SPSS. The uni-variant results are presented to the state legislature as an annual report. For the 2000 report, the Idaho Supreme Court blocked access to the pre-sentence investigations thus limiting the data that could be collected. While this annual study has been rewarding and beneficial to the state legislature, the authors have had a long term desire to expand the work (The annual report is conducted each year immediately after the close of the fiscal year resulting in a large number of cases not reaching conclusion before the end of data collection.) In 2003, the authors began work on a proposed recidivism study using cases from the annual report. A $10 \%$ random list of social security numbers was selected for each of the years 1991 through $2003^{1}$ using spss random sample option for those cases with known social security numbers. These social security numbers were provided to the Idaho Department of Correction (IDOC) to obtain additional data. Of the 604 social security numbers provided to the IDOC, additional information was returned on $447^{2}$. This research is based on those 447 randomly selected cases. Selected information was also obtained from IDOC electronic records for these 447 cases. This electronic IDOC information was combined with the data collected annually. The resulting data set contains a combination of variables from the two sources with recidivism information updated through 2005 . This means these offenders have exposure to recidivate in time periods ranging from 2 to 15 years. 


\section{Findings}

Large amounts of information have been gathered on those accused of child sexual abuse at the district court level in Idaho. Here we will limit our analysis to those variables we found reported in the published literature as having an association with recidivism for child sexual abuse or those our own research has shown are related to recidivism.

\section{Uni-variant Findings}

\section{Recidivism}

Recidivism is operationally defined as a "re-conviction for a crime, either a sexual or non-sexual felony." The authors are fully aware that this is not the only or even most desirable measure of recidivism but at the current stage of analysis it is the only available measure. If more complete access is allowed of the criminal records, pre-sentence investigations and sex offender evaluations, other measures will become available.

\section{All Recidivism}

Sixty one of the 447 show known recidivism of any kind. This means that the re-conviction rate for child sexual offenders over this 13 year period is $13.6 \%$. This rate included recidivism for any felony. This is generally low but it must be remembered that 13 years is not a long period of time and that re-conviction must be seen as a conservative estimate of actual re-offending based on the nature of this type of crime.

\section{Sex Crime Recidivism}

Forty one of the 447 show known recidivism for another sex crime (sex crime is a broader category than child sexual abuse). This means that the re-conviction rate for sexual abuse is no more that $9.2 \%$ over this 15 year period. Again, this recidivism rate should be seen as a low estimate but compared to official recidivism rates for other crime groups (for which comparisons are more legitimate), recidivism for child sexual abuse appears low (FBI Uniform Crime Report, 1999).

\section{Number of Re-Convictions}

While 13 years seems a long period, for longitudinal recidivism studies it is only moderate in length, especially since child sex abuse is difficult to detect and is under reported. Bricker and Beech (2001) reported that the average length of longitudinal studies was less than 2 years but have been as long as 30 years. For these 447 cases, 374 or $83.7 \%$ were only convicted once. Interestingly, 85 or $19 \%$ of these 447 cases have no record of any sex crime convictions, only other felonies. Again, every case had felony charges made in district court for child sexual abuse but many have their charges reduced to non-sex crime charges. Fifty eight or $13.0 \%$ of these 447 had two felony convictions for any felony while 38 or $8.5 \%$ have re-convictions for sex crimes. Three or $0.7 \%$ shows three convictions (all for child sexual abuse). Twelve or $2.7 \%$ have no record of convictions but are in the system possibly for violation of probation guidelines or awaiting the Pre-sentence Report.

\section{Sex Difference}

Females were the majority of the victims $(86.1 \%$ for the first victim) and males were the majority of the offenders (98\%). Fifty-four, or $14.2 \%$, of those with known genders were the same gender (males abusing males or females abusing females) and 327 or $85.8 \%$ were of different genders. 


\section{Age Difference}

The age difference between the offender and victim had a range of 71 years with a mean of 22.68 years and a standard deviation of 14.75 years. The age difference between offender and victim were as small as 2 years and as great as 73 years.

\section{Relationship to Victim}

For those with a known relationship, 152 or $43.9 \%$ were related in some way and 194 or $56.1 \%$ were not related (17 or $4.9 \%$ were strangers). The modal group was acquaintances. Step parents were included here in the related group although parents were the most common relative relationship.

\section{Ethnicity}

Idaho is predominately a Caucasian state and those convicted for child sexual abuse are no exception. For these 447 cases, 372 or $83.2 \%$ are Caucasian and 74, 16.6\% are Non-Caucasian, mostly Hispanic.

\section{Served Time in Prison or Probation}

While a large number of the cases were in legal flux, pre-sentence or retained jurisdiction (a sentence that gives the offender a "shock incarceration period" and the judge retains jurisdiction for 180 days for reevaluation), 209 are known to have started their first conviction either out of prison on probation $(\mathrm{N}=125$ or $59.8 \%)$ or incarcerated ( $\mathrm{N}=84$ or $40.2 \%$ ). It can be assumed that those incarcerated might be seen as a more dangerous threat to recidivate but incarceration will reduce their time at risk.

\section{Time at Risk}

These data were a random sample drawn from all cases filed in district court from 1991 through 2003. It is logical that those committing their first offense early, around 1991, would have a greater likelihood of recidivating that those committing their first offense later, closer to 2003 as they are likely to have more time at risk to recidivate. The 10\% sample was drawn from each year of the annual studies. It was assumed that even with missing data and other data issues, the numbers for each year would be close to the same. While there is variability, this appears to be the case. The lowest year comprised $6.1 \%$ of the cases while the highest year comprised $13.7 \%$. It should be kept in mind that each year was sampled separately and there where variations in the numbers charged each year. As stated in the introduction, the electronic data from the IDOC was obtained near the end of 2005 meaning that offenders were at risk to recidivate for a time period of 2 to 15 years. Even the low end of this time range was greater than the majority of longitudinal studies.

\section{Sex Offender Treatment}

Those convicted of child sexual abuse can be offered sex offender treatment. In this sample 64 or $14.3 \%$ of those convicted received sex offender treatment on one or more occasions. One hundred and sixty one or $36.1 \%$ received other types of treatment or training and 221 or $49.6 \%$ received no treatment/training.

\section{Age of Victim}

Some research shows that those abusing pre-pubescent children are more likely to recidivate than those abusing post-pubescent children (the normal cut off is 13 years of age for pre-pubescent). Almost $54 \%$ of the first victims with known ages were 13 or younger while $46.4 \%$ were 14 or older. 


\section{Sex Offender Evaluation}

While every offender convicted of child sexual abuse was originally required to receive a Sex Offender Evaluation in Idaho (Idaho Code 18-8316) based on legislation passed in 1998, the law was modified in 1999 to make it optional to require the evaluation. Consequently, most in Idaho convicted of a child sex offense do not have a Sex Offender Evaluation completed before sentencing in this state. (The annual child sexual abuse report collects data very soon, a year or less, after the filing of charges in district court, only 97 or $22.1 \%$ of the 447 in the sample are recorded as receiving one. Of these 97,24 or $24.7 \%$ were estimated to have a High probability of re-offense, 32 or $33.0 \%$ were estimated to have a Moderate probability of re-offense, and 41 or $42.3 \%$ were estimated to have a Low probability.)

Sex offender evaluations were completed at both state facilities (for those sent to retained jurisdiction) and by private providers for those on probation/parole. In all cases there are criteria established by the state for what is included in the sex offender evaluations (Idaho Code 18-8316). The guidelines for the psychosexual evaluation reports include demographic variables, a social history, and an assessment of sexual behavior including self reports, and standard personality testing. This information, combined with a face to face interview with the state certified evaluator results in, among other things, an estimate of risk level.

\section{Bi-variant and Tri-variant Analysis}

The following bi-variant analyses are based on Pearson's zero order correlations. All variables are either interval/ratio or dichotomous making the use of interval/ratio measures of association appropriate at this bi-variant analysis.

\section{Ethnicity by Recidivism}

Ethnicity, either White or Non-white had no significant correlation with recidivism for sex crimes $(\mathrm{r}=.05$, sig. $=$ .33) but did show a significant if weak correlation with recidivism in general $(\mathrm{r}=.10$, sig. $=.04)$. Controlling for cohort, year entering the study, lowered the correlation only slightly and they remain non-significant. This was both encouraging and troubling at the same time. It is encouraging in that ethnicity doesn't seem to be associated with sex crime recidivism but is troubling in that minorities do seem to be more likely to be convicted for additional crimes. This research appears to differ from other reports in showing that there seems to be no significant relationship between ethnicity and child sexual abuse.

\section{Sex Difference by Recidivism}

Whether one abuses a victim of their same sex or the opposite sex does not appear to correlate with recidivism. The correlation between sex difference and recidivism in general and recidivism for sex crimes was both very small (less than 0.02) and not significant. Controlling cohort did not change this correlation.

\section{Age Difference by Recidivism}

The authors own research has shown that the age difference between the offender and the victim is one of the variables that affect the length of sentence received. It was also thought that this relationship might hold for recidivism. It did not appear to be the case with these data. The correlations between age difference and recidivism in general and for sex crime are 0.03 or lower and not significant. Controlling cohort did not change this correlation at all. 


\section{Relationship by Recidivism}

Strangers or those not related to their victims appeared no more likely to recidivate than those related to their victim. Unfortunately much of the media hype and public laws passed by both Congress and state legislatures relates to this mythical stereotype of stranger victimization (Kappeler and Potter, 2004). The correlations between relationship and recidivism in general and for sex crime were 0.05 or lower and not significant. Controlling for cohort lowered this correlation slightly.

\section{Initial Status by Recidivism}

For the limited number of cases where the initial status was clearly in prison or out of prison, the correlation between being in prison or out on probation was small for both general recidivism and recidivism for sexual crimes (.13 and .09 respectively) and not significant. It seems prison confinement for the first conviction was not related to future reductions in recidivism. Controlling cohort did not change this correlation.

\section{Time at Risk by Recidivism}

Those being convicted of child sexual abuse earlier in the longitudinal time line did not appear to be more likely to recidivate than those convicted later in the study. With correlations for general recidivism at .03 and for sex crime recidivism at -.03 (and neither significant), it seemed for the measure of time at risk, time does not matter.

While the above correlation between time at risk and recidivism was based on pooling the years and using years since first offense as the independent variable, both survival analysis and logistic regression showed no significant relationship between time at risk and recidivism.

\section{Sex Offender Treatment by Recidivism}

Those who received some measure of sex offender treatment do appear less likely to recidivate for both general crimes and sex crimes (-.12 and -.07 respectively) but these correlations were small and not significant. Treatment, any type, as measured in this study did not appear to reduce recidivism. It should be noted that these data did not differentiate between treatments while incarcerated or while in the community. Furthermore, the treatment category was larger than simply sex offender treatment. Controlling cohort did not change this correlation.

\section{Victim Age by Recidivism}

Those whose victims were prepubescent or post-pubescent show no significant differences in either general recidivism $(\mathrm{r}=.01)$ or sex offender recidivism $(\mathrm{r}=.01)$. Controlling cohort did not change this correlation at all. It doesn't appear that those abusing younger children were more likely to recidivate that those abusing older children/adolescents.

\section{Sex Offender Evaluation by Recidivism}

Sex Offender evaluations did not seem to have a significant correlation with recidivism in general $(\mathrm{r}=.195$, sig. $=$ .06) but do show a significant correlation with sex crime recidivism

$(\mathrm{r}=.26$, sig. $=.01)$. The higher the estimate of repeat probability, the higher the likelihood of recidivism for sex crimes. This correlation drops to a slightly weaker, $r=.20$, when cohort year

was controlled and was still significant. While time at risk lowered the correlation slightly, sex offender evaluation risk of repeat probability was still the only measure that has any predictive value in these data. This showed sex offender evaluations have some utility in predicting future sex crimes. 


\section{Discussion}

This research showed that the confusion present in the literature on child sexual abuse recidivism is well founded (Bricker and Beech, 2001). While other research has shown associations between recidivism and all of the variables in this study, there appears to be limited support for any of them in the data collected by the researchers to date, at least not at this initial bi-variate level of analysis. The only significant and almost moderate association seen is between recidivism and the sex offender evaluation report of probability of re-offense.

\section{Sex Crimes General}

The data showed that, with the exception of gender of offender, sex offenders did not seem to differ from the general population in ethnicity. Sex difference between the offender and victim as well as age difference showed no significant association with recidivism. Additionally, it appeared from these longitudinal data that there was a generally low level of recidivism among sex offenders when compared to other criminal groups. Strangers were a very small minority of offenders and these have been shown to often be the most violent. It appeared that the news media reports are sensationalistic and are leading to legislation applicable to many offenders but only appropriate to a few. It also appeared to indicate that news media constructions of the dynamics of child sex offenders resulted in both inaccurate portrayals and questionable public policies (Kappeler and Potter, 2004)

\section{Recidivism}

As stated above, recidivism among these sex offenders in this study was generally low. Additionally, there seemed to be no significant differences by ethnicity in recidivism rates. It was unfortunate that minorities did seem to be more likely to recidivate at higher rates than Caucasians. It was unclear whether this increased likelihood of recidivism for minorities was due to increased criminal activity among minorities or inequality in the criminal justice system. Prior research points to the latter rather than the former (Walker, Spohn, and DeLone, 2007).

\section{Sex Offender Evaluation by Recidivism}

Of all the variables we have initially analyzed, only Sex Offender Evaluation for probability of repeat offense showed any substantial association with recidivism. This was both significant and almost moderate. The higher the predicted probability of repeat offense in the optional Sex Offender Evaluation, the higher the likelihood of recidivism. This finding only underscores the importance of Sex Offender Evaluations. Unlike the other findings not confirmed by this research, a professional evaluation, while not perfect, appears to work in prediction. This finding calls for more research on sex offender evaluations, best practices and finding ways to encourage the legislature and the courts to both require and use them. Even with a small sample size, an almost moderate and significant association was obtained. Other research has criticized clinical evaluations as predictors but based on these random data it seems the only clear predictors are these clinical evaluations (Bickley and Beech, 2001).

While psychological theories have been seen as lacking in understanding child sexual abuse (Sawle and KearColwell, 2001; Bickley and Beech, 2001; Joyce, 1995), it seems from this initial research that psychological measures are of some utility. While personality inventories like MMPI have their limits, they are among the best tools currently available. What is more interesting is the flexibility the evaluators have in determining the risk level. They are required to test and obtain information from the convicted sex offender but the method by which they come to their risk level assessment is purposely vague. There is no set formula and individual evaluators are left to their professional expertise in determining what parts of the evaluation to use in each individual case. While this gives the evaluator significant autonomy and considerable power, it does little to help researchers and governments determine what specific factors can be used to predict recidivism. Based on the professional preparation of the evaluators ranging from M.D.'s with psychiatric specialties to M.A. level counselors, there is little required objectivity in the reports. 


\section{Conclusion}

This initial analysis has shown several things. First, recidivism among child sexual offenders was generally lower than expected or believed. Second, while minorities in the state were more likely to re-offend in general, ethnicity played no significant part in recidivism for child sexual abuse. Finally, from this initial analysis it appeared that a sex offender evaluation was the only significant predictor of future recidivism for child sexual abuse.

What this evident from this initial analysis was the need for more research to not only balance the media hysteria leading to uninformed legislation but also to fully determine the variables associated with recidivism for child sexual abuse. Not only was more research needed but access to existing data collected in great abundance by state agencies needs to be released to researchers. The names and addresses of known child sexual abusers are routinely placed on web sites for all to access as well as pictures and newspaper announcements. Less identifiable information that could assist researchers and ultimately law enforcement and legislatures in preventing child sexual abuse is hidden away, unused.

Sex offender evaluations appeared to be the most important predictor of child sexual abuse recidivism to be initially found in these data. It is important as a matter of public policy that ways are found to encourage that these reports be done on all those convicted of child sexual abuse.

This research, hampered as it is by bureaucratic and legal restrains, has been on adults. Research is needed on juvenile offenders. If those with a predilection for child sexual abuse can be identified early enough, they may be treatable and in any case some of their victims in adulthood might be saved.

This work, initial as it is, exhibits many limitations. While it is a random sample of all offenders charged at the district court level with child sexual abuse for 13 years in the entire state, the data have many of the problems seen in other research. These data are a combination of data collected by the authors and data collected by the Department of Correction. The goals of the authors and the Department of Correction are different and the data collected is different. Many demographic variables are recoded in the state data to such an extent as the be of little use to the researchers and the state's legal resistance to allowing the researchers access to the full files for these offenders limits the data available.

Additionally, this has been a simple bi-variant analysis and where possible a further, multi-variant analysis is needed. Child sexual abuse has resisted analysis for years and a simple solution to understanding this process seems unlikely. In all cases and at all levels treatment is needed for both offenders and victims of child sexual abuse (Shanahan and Donato, 2001) and more research is needed to see what treatment programs work, if any. Finally, coherent theory is needed to guide research and understand child sexual abuse.

\section{Endnotes}

1. For the years 1991 through 2003, two years, 1993 and 2000, are not included. For 1993 data the authors were making the transition from main frame analysis of the data to PC based analysis, while the hard copy of the data exist, the computer based data where lost in the transition. It was decided for this initial analysis 1993 would be excluded. There appear to be no significant differences between 1993 and the surrounding years. In 2000 the Idaho Supreme Court decided that the authors where no longer allowed access to pre-sentence investigation reports for confidentiality reasons. For 2000 social security numbers were not recorded thus making it impossible to select a random sample for this year. Again, the year 2000 does not seem significantly different from the surrounding years. In conclusion, the exclusion of these two years, while regrettable, does not seem to affect the results of this analysis. 
2. There are a large number of potentially complicated reasons data were not available for over 150 of the cases requested from the department of corrections. A significant reason is likely the random nature of the analysis. In each years report $10 \%$ to $15 \%$ if the charges filed are acquitted or dismissed. If these case have no other convictions there is no reason they would be in the records of IDOC. This means that 60 to 90 of the 600+ cases should not be in the records. Addition reasons may also be coding errors on the part of the authors, incorrect social security numbers in the records and/or missing information in the electronic data recorded by the department of corrections. An analysis comparing the cases for which data is available and the missing data shows no significant differences.

\section{References}

Anderson, J. F., Mangels, N. J., \& Langsam, A. (2004). Child sexual abuse: A public health issue. Criminal Justice Studies: A Critical Journal of Crime, Law and Society, 17(1) 107-126.

Bickley, J., \& Beech, Anthony. (2001). Classifying child abusers: Its relevance to theory and clinical practice. International Journal of Offender Therapy and Comparative Criminology, 45(1), 51-69.

Cheit, R. E. (2003). What hysteria? A systematic study of newspaper coverage of accused child molesters. Child abuse \& neglect, 27(6) 607-623.

Cullen, B. J., Smith, P. H., Funk, J. B., \& Haaf, R. A. (2000). A matched cohort comparison of a criminal justice system's response to child sexual abuse: A profile of perpetrators. Child Abuse and Neglect, 24(4) 569-577.

Danni, K., \& Hampe, G. (2000). An analysis of child sex offender types using presentence investigation reports. International Journal of Offender Therapy and Comparative Criminology, 44(4) 490-504.

Federal Bureau of Investigation Uniform Crime Report. (1999). Http://www.fbi.gov/ucr/99cius.htm.

Fisher, D., \& Mair, G. (1998). A review of classification systems for sex offenders. Edinburgh: Scottish Office.

Freund, K., \& Watson, R. J. (1992). The proportions of heterosexual and homosexual pedophiles among sex offenders against children: An exploratory study. Journal of Sex and Marital Therapy, 18(1) 34-43.

Greenberg, D., Bradford, J., Firestone, P., \& Curry, S. (2000). Recidivism of child molesters: A study of victim relationship with the perpetrator. Child Abuse and Neglect, 24(11) 1485-1494.

Gudjonsson, G. H., \& Sigurdsson, J. F. (2000). Differences and similarities between violent offenders and sex offenders. Child Abuse and Neglect, 24(3) 363-372.

Hagan, M. P., \& Gust-Brey, K. L. (2000). A ten-year longitudinal study of adolescent perpetrators of sexual assault against children. Journal of Offender Rehabilitation, 31(1-2) 117-126.

Hall, G. (1996) Theory-based Assessment, Treatment, and Prevention of Sexual Aggression. Oxford, UK: Oxford University Press.

Hanson, R. K., Scott, H., \& Steffy, R. A. (1995). A comparison of child molesters and nonsexual criminals: Risk predictors and long-term recidivism. Journal of Research in Crime and Delinquency, 32(3) 325-337.

Idaho Code. Title18, Section 8314.

Idaho Code. Title18, Section 8316. 
Jones, L. M., Finkelhor, D., \& Kopiec, K. (2001). Why is sexual abuse declining? A survey of state child protection administrators. Child Abuse and Neglect, 25(9) 1139-1158.

Joyce, P. A. (1995). Psychoanalytic theory, child sexual abuse and clinical social work. Clinical Social Work Journal, 23(2) 199-214.

Kaufman, K. L., Wallace, A. M., Johnson, C. F., \& Reeder, M. L. (1995). Comparing female and male perpetrator's modus operandi: Victims' reports of sexual abuse. Journal of Interpersonal Violence, 10(3) 322-333.

Kappeler, Victor and Potter, Gary. (2004). The Mythology of Crime and Criminal Justice. Illinois: Waveland Press. $4^{\text {th }}$. Edition.

Langevin, R., Curnoe, S., Fedoroff, P., Bennett, R., Langevin, M., \& Peever, C. et al. (2004).Lifetime sex offender recidivism: A 25-year follow-up study. Canadian Journal of Criminology and Criminal Justice/Revue canadienne de criminologie et de justice penale, 46(5) 531-552.

Marsh, R. \& Walsh, A. (1995). Physiological and Psycho social Assessment and Treatment of Sex Offenders: A Comprehensive Victim-Oriented Program. Journal of Offender Rehabilitation, 22(1,2).

McAlinden, A. (2005). The use of 'shame' with sexual offenders. British Journal of Criminology, 45(3) 373-394

Petrunik, M. (2003). The hare and the tortoise: Dangerousness and sex offender policy in the united states and canada. Canadian Journal of Criminology and Criminal Justice/Revue canadienne de criminologie et de justice penale, 45(1) 43-72.

Prentky, R. A., Lee, A. F. S., Knight, R. A., \& Cerce, D. (1997). Recidivism rates among child molesters and rapists: A methodological analysis. Law and human behavior, 21(6) 635-659.

Prentky, R. A., Lee, A. F. S., Knight, R. A., \& Cerce, D. (1997). Recidivism rates among child molesters and rapists: A methodological analysis. Law and human behavior, 21(6) 635-659.

Sawle, G., \& Kear-Colwell. (2001). Adult Attachment Style and Pedophilia: A Developmental Perspective, International Journal of Offender Therapy and Comparative Criminology, 45(1). 32-50.

Shanahan, M., \& Donato, R. (2001). Counting the cost: Estimating the economic benefit of pedophile treatment programs. Child Abuse and Neglect, 25(4) 541-555.

Tzeng, O. C. S., Robinson, R. L., \& Karlson, H. C. (1999). Demographic correlates and judicial determinations of child sexual abuse offenses. Journal of Social Distress and the Homeless, 8(2) 55-77.

Walker, Samuel, Spohn, Casia, and DeLone Miriam (2007). The Color of Justice. California:

Thomson Publishing. $4^{\text {th }}$ Edition. 